\title{
Flexible low-cost system to test batteries and ultracapacitors for electric and hybrid vehicles in real working conditions
}

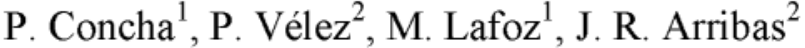 \\ ${ }^{I}$ Pablo Concha (corresponding author), CIEMAT (research organization), SPAIN, pablo.concha@ciemat.es \\ ${ }^{2}$ Universidad Politécnica de Madrid, SPAIN
}

\begin{abstract}
Batteries and ultracapacitors for hybrid and electric vehicles must satisfy very demanding working conditions that are not usual in other applications. In this sense, specific tests must be performed in order to draw accurate conclusions about their behaviour. To do so, new advanced test benches are needed. These platforms must allow the study of a wide variety of energy storage systems under conditions similar to the real ones. In this paper, a flexible, low-cost and highly customizable system is presented. This system allows batteries and ultracapacitors to be tested in many and varied ways, effectively emulating the working conditions that they face in an electric vehicle. The platform was specifically designed to study energy storage systems for electric and hybrid vehicles, meaning that it is suitable to test different systems in many different working conditions, including real driving cycles. This flexibility is achieved keeping the cost of the platform low, which makes the proposed test bench a feasible alternative for the industry. As an example of the functionality of the platform, a test consisting of a 17-minute ARTEMIS urban cycle with a NiMH battery pack is presented.
\end{abstract}

Keywords: energy storage, battery testing, converter, driving cycle.

\section{Introduction}

Nowadays, the energy storage system (ESS) of an electric vehicle (EV) is probably the bottleneck for the feasibility of electromobility [1]. Batteries and ultracapacitors are also an important component of hybrid vehicles (HV). For this reason, major focus has been put on this key element, research included. New types of batteries and ultracapacitors are proposed every year [2][3], and novel systems are developed continuously, such as hybrid systems that combine both of them [4][5].
In this context, the need for ESS testing platforms is high. The kinds of tests to perform with these platforms are not conventional simple tests anymore, such as constant current or constant power tests. In order to draw accurate conclusions specific for EVs, more complex test must be carried out. For example, it is undeniably interesting to make the ESS work in the same way as it would in a typical driving cycle, such as the ARTEMIS European driving cycles [6].

Moreover, to build a flexible test bench means to be able to test different ESS devices (batteries of different types, ultra-batteries, ultracapacitors, and combinations of them). These systems may have different voltage ranges, power, and capacity, and 
they may be combined in different configurations (batteries in series, in parallel, with or without ultracapacitors, and so on). To be able to study all this alternatives with the same test bench is the goal of the proposed test bench.

Naturally, this requires an advanced test platform with high flexibility and high degree of customization. Some systems of this type have been recently proposed in the literature. Most of them are very low power demonstrators [7][8], while others are conceived to test high voltage EES based on batteries only [9][10]. There are also commercial devices available with such features, but they have either low power or a prohibitive cost.

In this paper, a flexible, affordable and highly customizable laboratory test bench is proposed as an alternative. This platform was born to overcome the disadvantages of previously existing systems (either technical limitations or price), and was specifically designed to test ESS for hybrid and electric vehicles. In this sense, focus was put in high currents rather than high voltages.

The paper presents the detailed construction and the operation mode of the different components of the test bench, including protections, alarms and other safety issues. The testing facilities and the control system are also described. Finally, a test consisting of a NiMH battery pack working in the same conditions as in an urban ARTEMIS cycle is presented as an example of the functionality of the system.

\section{Description of the test bench}

The proposed system, shown in Fig.1, was designed trying to keep the topology as straightforward as possible. It cannot be considered a simple system, but its flexibility and open functionality are achieved with a very reasonable grade of complexity.

The test bench consists of the ESS under study (batteries, ultracapacitors, or combinations of both), a DC/DC power electronic converter, a $\mathrm{DC} / \mathrm{AC}$ power electronic converter, and a tapped transformer connected to the low voltage grid. This topology allows the grid to exchange power with the ESS, whatever its voltage is, while the DC link voltage is kept constant. In this sense, the DC/AC converter emulates the inverter of a traction system, by continuously exchanging power between the grid, which emulates the traction motor, and the ESS.

One of the advantages of the proposed set-up is its flexibility. In this case, low voltages and high currents were to be achieved, so the system was designed consistently. However, higher voltages (up to $400 \mathrm{~V}$ ) are also achievable with the same topology. This would mean either lower current (with the same hardware), or higher power equipment. In this sense, the rated power of the assembled test bench could easily be increased three or four times (the transformer ratio would be different in that case).

In the assembled system, the rated voltage of the ESS must be comprised between 12 and $96 \mathrm{~V}$. The rated power of the two electronic converters is 15 $\mathrm{kVA}$, which allows charge/discharge currents up to $300 \mathrm{~A}$ or even more.

\subsection{Description of the power system}

The power system may be divided into two differentiated parts: the ESS side converter, depicted in Fig.2, and the grid side converter, in Fig.3. The former comprises the ESS itself, three inductances and the DC/DC converter; while the later comprises the $\mathrm{DC} / \mathrm{AC}$ converter, another three inductances, the transformer, and the capacitors pre-charge circuit. Both parts share the DC link existing between the two converters. The capacitors that constitute this link belong to both converters.

It is important to note here that, although both converters are exactly the same topologically speaking, they have different functionality. Their different mode of operation is due to the way they are connected to the rest of the system and to the way they are controlled. The fact that both devices are the same is another advantage of the proposed test bench, since its overall complexity is lowered.

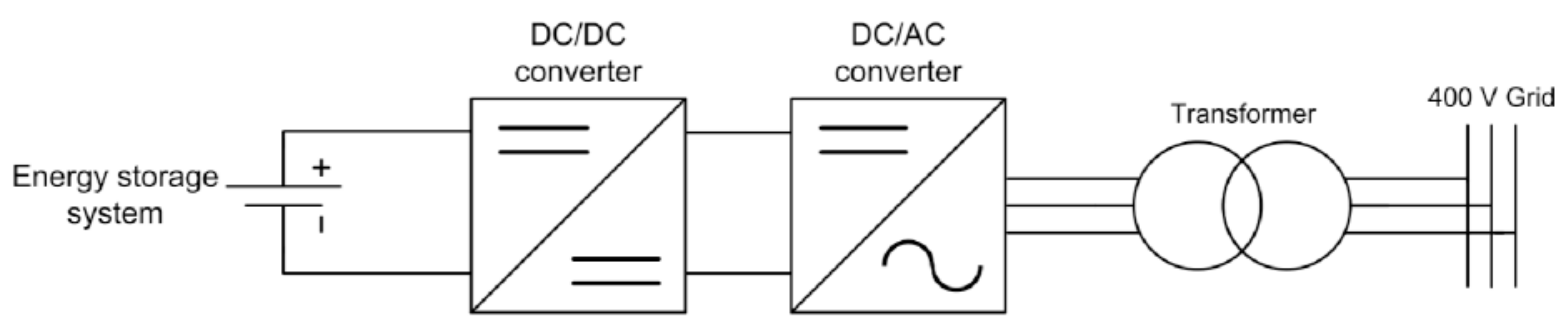

Figure 1: High current $15 \mathrm{~kW}$ ESS test bench. 


\subsubsection{ESS side (DC/DC converter)}

The first element of this part of the test bench is the ESS itself. As stated previously, the platform is designed to work with ESS of different nature, meaning that any kind of battery or capacitor may be tested, regardless its capacity, as long as its voltage is within a specific range (from 12 to $96 \mathrm{~V}$ in this case).

To achieve a suitable voltage, the battery modules may be connected in a proper series/parallel configuration. For instance, to test a $12 \mathrm{~V}$ lead-acid battery, four modules could be connected in series so that $48 \mathrm{~V}$ is the resulting rated voltage of the ESS. If more capacity was desired, another four-module branch could be connected in parallel with the first.

Although the voltage range is rather wide, it is preferable to keep the ESS voltage around 40-75 V. Lower or higher voltages make the system less stable and less efficient, since it was originally designed for that narrower range. Besides, very low voltages imply lower powers, since the currents are limited by the power electronics.

The ESS is connected to the DC/DC converter by means of three parallel wires, each of them being connected to one of the three branches of the converter. The reason to do this is to triple the maximum allowed charge/discharge current of the system, since each of the branches deals with approximately one third of the total current. This way, the full current capability of the converter is used.

To improve current ripple, three inductances are needed, one for each branch. These inductances behave as a filter for the DC current. Again, dividing the current into three smaller inductances is advantageous, given that it results in a more economic system. In the assembled platform, 3 $\mathrm{mH}$ inductances were used.

Finally, the bidirectional DC/DC converter, which topology is also depicted in Fig.2, is responsible for the DC/DC energy conversion. This classical low-voltage topology [11] works here as a conventional buck-boost converter with three

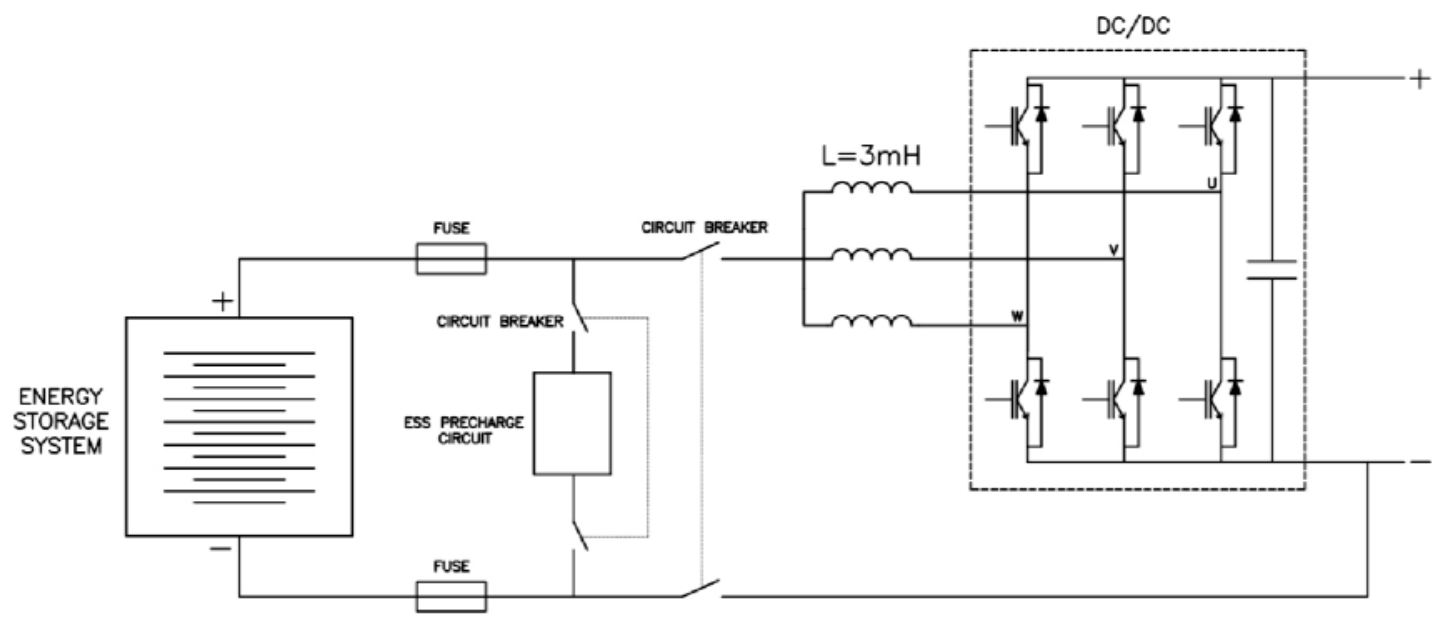

Figure 2: Structure of the ESS and the DC/DC converter.

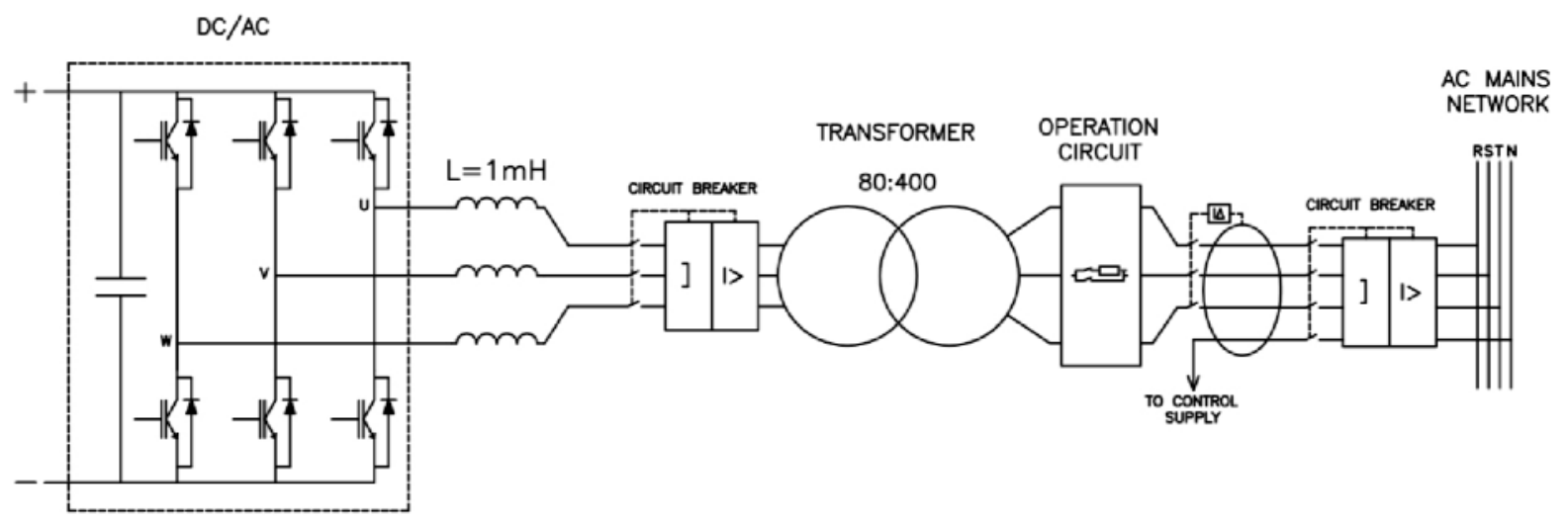

Figure 3: Structure of the DC/AC converter and the grid connection. 
parallel branches (interleave topology). The DC/DC converter dynamically adapts the ESS voltage while keeping the DC link voltage constant at $150 \mathrm{~V}$. By doing this, it is possible to instantly control the current flowing to/from the ESS, allowing it to discharge (give power) and charge (absorbing power) at will. An additional advantage is achieved by decaving the PWM signals of every branch one third of the commutation period, to reduce the current ripple. Besides the aforementioned elements, the ESS side converter has some auxiliary devices as well, the most important being a DC fuse (to protect in case of short-circuit) and a DC contactor (to make sure that the batteries are in open-circuit when not working).

\subsubsection{Grid side (DC/AC converter)}

The second part of the power system is responsible for the connection to the grid. Through this connection, the power flow between the ESS and the grid is effectively: controlled.

The grid side converter is a DC/AC converter comprised of a second power electronics unit. a transformer, and an inductive link between both. The DC/AC converter is connected to the $\mathrm{DC} / \mathrm{DC}$ converter so that both $\mathrm{DC}$ links are directly joined. This means that the total capacity. of the equivalent DC link is twice the capacity of each individual converter, which is advantageous for both of them.

The topology of the DC/AC converter is exactly the same as the $\mathrm{DC} / \mathrm{DC}$ converter, shown in Fig.3. As with that converter, the DC/AC converter is also bidirectional, which means that it allows the power to flow either towards the grid (inverter mode), or towards the DC link (controlled rectifier mode).

The main goal of the DC/AC converter is to control the power exchanged with the grid, both active and reactive power. Active power is controlled so that the DC link voltage is kept constant at a certain value $(150 \mathrm{~V}$ in the assembled system). This value is far from being arbitrary, since:

- It must be high enough to allow the current commutation at the grid voltage level:

$$
U_{D C}>\frac{2 \sqrt{2}}{\sqrt{3}} \cdot U_{2}=\frac{2 \sqrt{2}}{\sqrt{3}} \cdot \frac{U_{1}}{a_{T}}
$$

where $U_{D C}$ is the $D C$ link voltage. $U_{1}$ and $U_{2}$ are the primary and secondary transformer voltages, and $\mathrm{a}_{\mathrm{T}}$ is its transformation ratio.

- It cannot be too high, because of instability and efficiency issues. The higher the voltage ratio (defined as the DC link voltage divided by the ESS voltage), the more unstable and inefficient the system.

In the assembled system, which has a 400:80 transformer $\left(U_{D C}>136 \mathrm{~V}\right)$, a value of $150 \mathrm{~V}$ was chosen, which is very suitable for ESS in the range $40.75 \mathrm{~V}$. For lower voltage ESS, that value is reduced up to $136 \mathrm{~V}$ to benefit from a lower voltage ratio.

As with the $D C / D C$ converter, an inductive link is needed at the $\mathrm{AC}$ output of the $\mathrm{DC} / \mathrm{AC}$ converter. which works as a filter. The value of these inductances is $1 \mathrm{mH}$ in the assembled system.

As implicitly stated above, in order to have a suitable $\mathrm{AC}$ voltage at the $\mathrm{DC} / \mathrm{AC}$ converter output, a transformer is necessary. This way, the $400 \mathrm{~V}$ of the distribution grid is reduced to a lower value. Besides, the transformer provides galvanic isolation, but at the cost of reduced efficiency:

Finally, an operation circuit, consisting in limiting resistors, is used to reduce the DC link initial charging current as well as the transformer magnetizing current at system start-up. This circuit is installed between the transformer and the grid. Besides, some protections are also placed at this point (conventional circuit breakers).

\subsection{Description of the control system}

In this section, both the control hardware and the control software are described briefly:

\subsubsection{Control hardware}

The control hardware comprises electrical and thermal measurements, a digital signal processor (DSP) and a personal computer (PC).

In all, 8 electrical measurements ( 4 voltages and 4 currents, shown in Fig.4) and 6 thermal measurements (ambient, DC/DC converter, $\mathrm{DC} / \mathrm{AC}$ converter, and up to three for the ESS) are taken by means of Hall sensors and Ptlo0 sensors, respectively:

The control software runs in a prototyping DSP from dSPACE, model DSII04. This DSP is connected to a PC for software development and monitoring purposes 


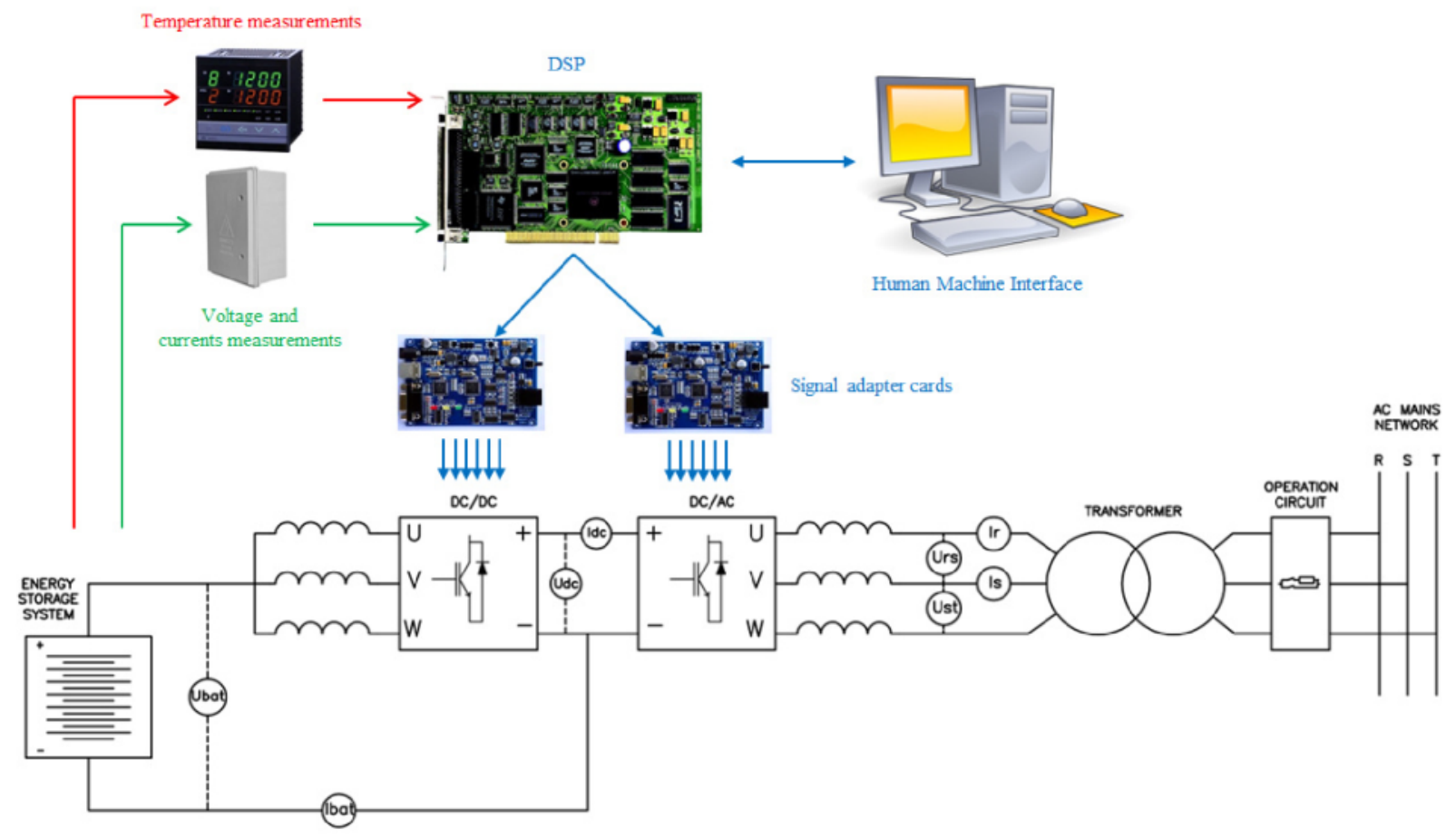

Figure 4: Control hardware scheme.

\subsubsection{Control software}

The control software has two main elements: the control software itself and a human-machine interface (HMI).

The control software has three main purposes:

- Measurements filtering and post-processing.

- Generate the switching commands for the $\mathrm{DC} / \mathrm{DC}$ and the DC/AC converters according to the corresponding control strategies.

- Data recording.
The 3-phase DC/DC converter is controlled as three different single phase DC/DC converters, each of the phases dealing with approximately one third of the total current. This converter is responsible for controlling the current in the ESS regardless its voltage. The control strategy is a PWM current control with a constant switching frequency of $5 \mathrm{kHz}$. All three branches are controlled the same way; their duty cycles being defined by the comparison with a high-frequency triangular waveform. In order to lessen the

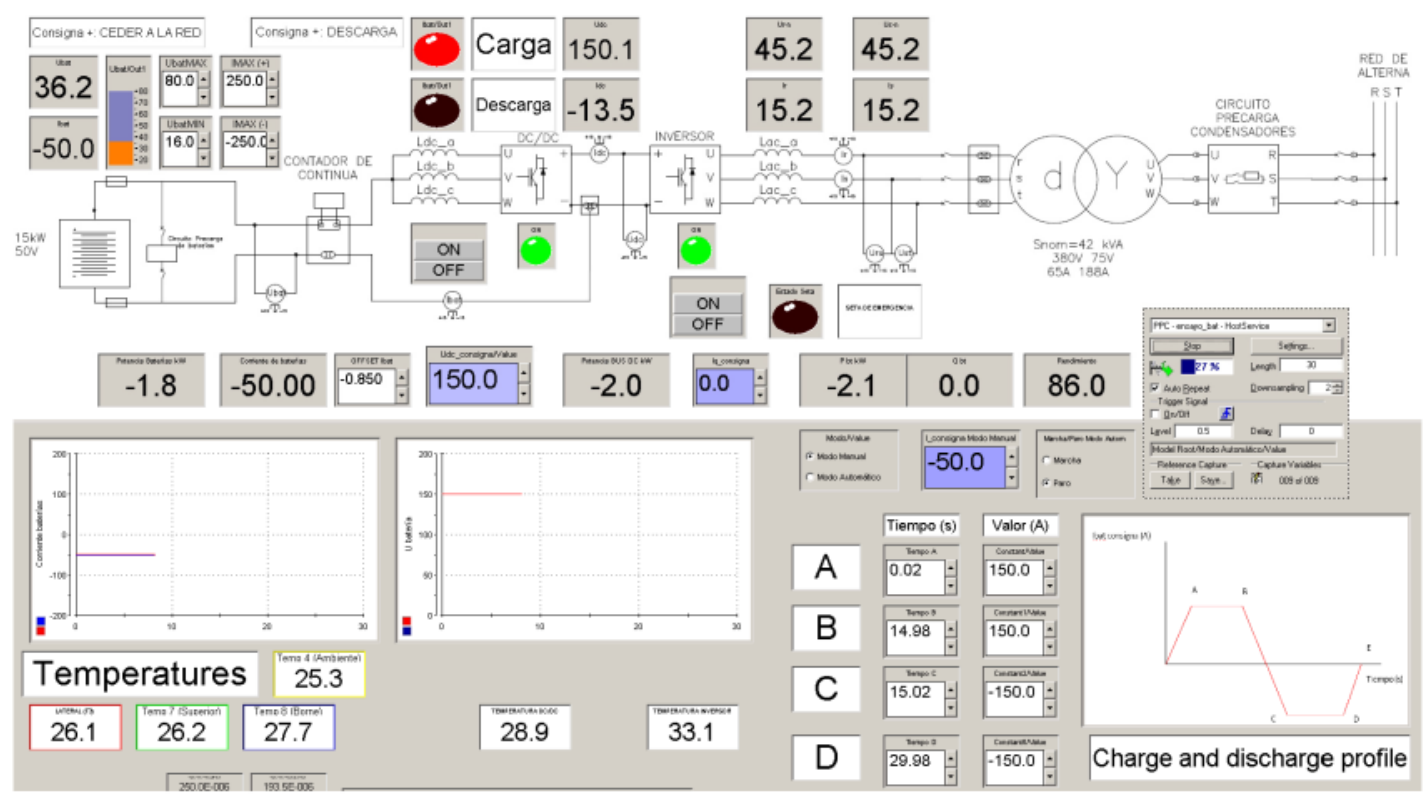

Figure 5: Human machine interface. 
harmonic content of the ESS current, the three triangular waveforms are generated with a 120 degrees phase shift, therefore reducing the current ripple to one third.

The DC/AC converter is controlled as a conventional grid-tie inverter with reactive power control capability. This converter is responsible for controlling both the $\mathrm{DC}$ voltage in the DC links and the reactive power exchanged with the grid. The control strategy is a SVPWM current control with a constant switching frequency of $5 \mathrm{kHz}$.

The HMI, shown in Fig.5, allows for effective operation, control and monitoring of the platform. From here, the operator can perform and record tests with the desired current profile.

\subsection{Description of the facilities}

All the power equipment, except the batteries and the ultracapacitors, is placed inside an air-cooled electric cabinet as illustrated in Fig.6.

All the energy storage systems are located inside a safety room, shown in Fig.7, with temperature control and fire suppression systems available.

\subsection{System performance and cost}

The test bench has been tested with charge/discharge currents up to $300 \mathrm{~A}$. Concerning

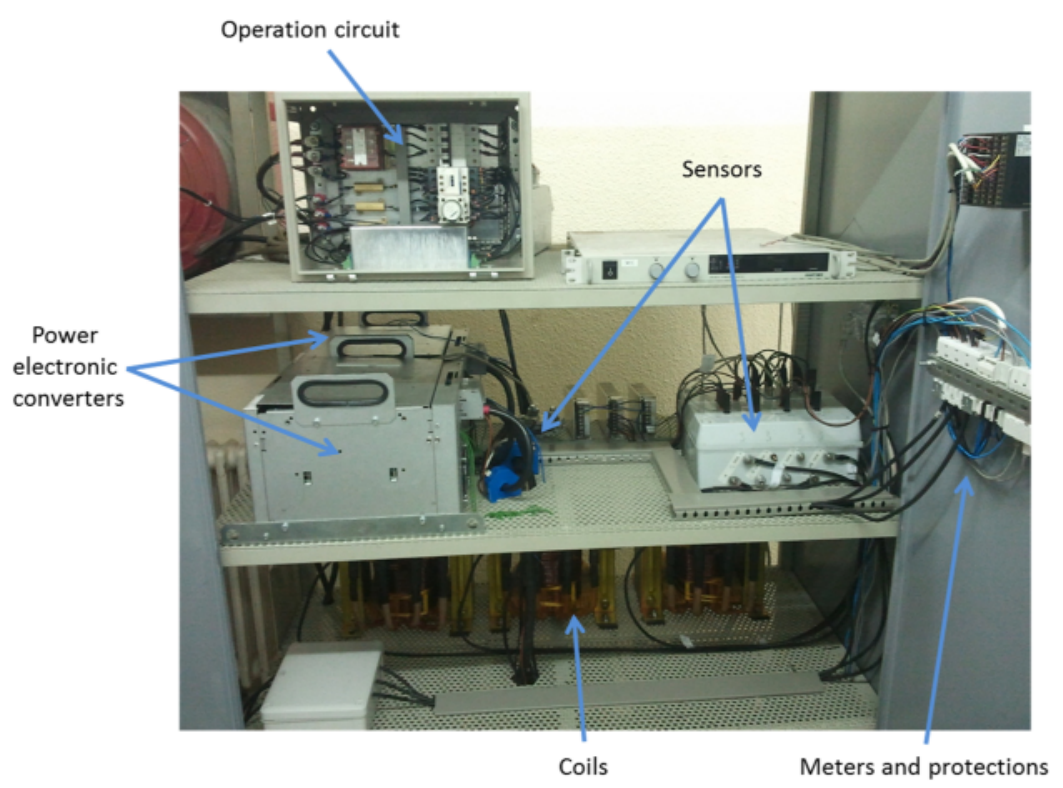

Figure 6: Electric cabinet containing both converters, the coils, the sensors and some protections.

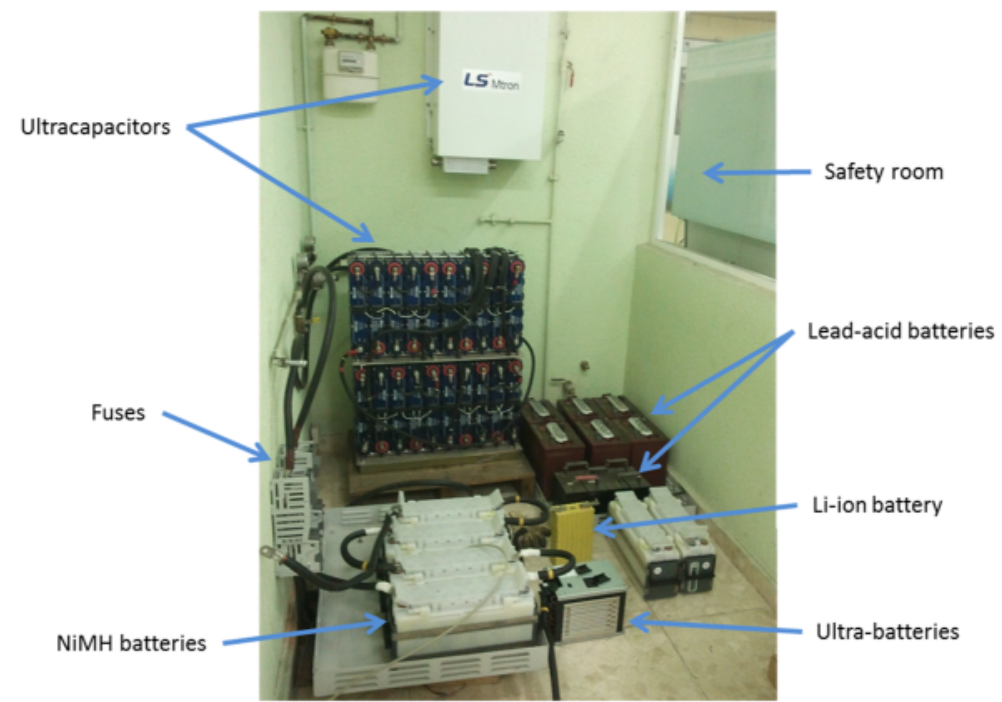

Figure 7: Safety room for batteries and ultracapacitors with different types of EES inside. 


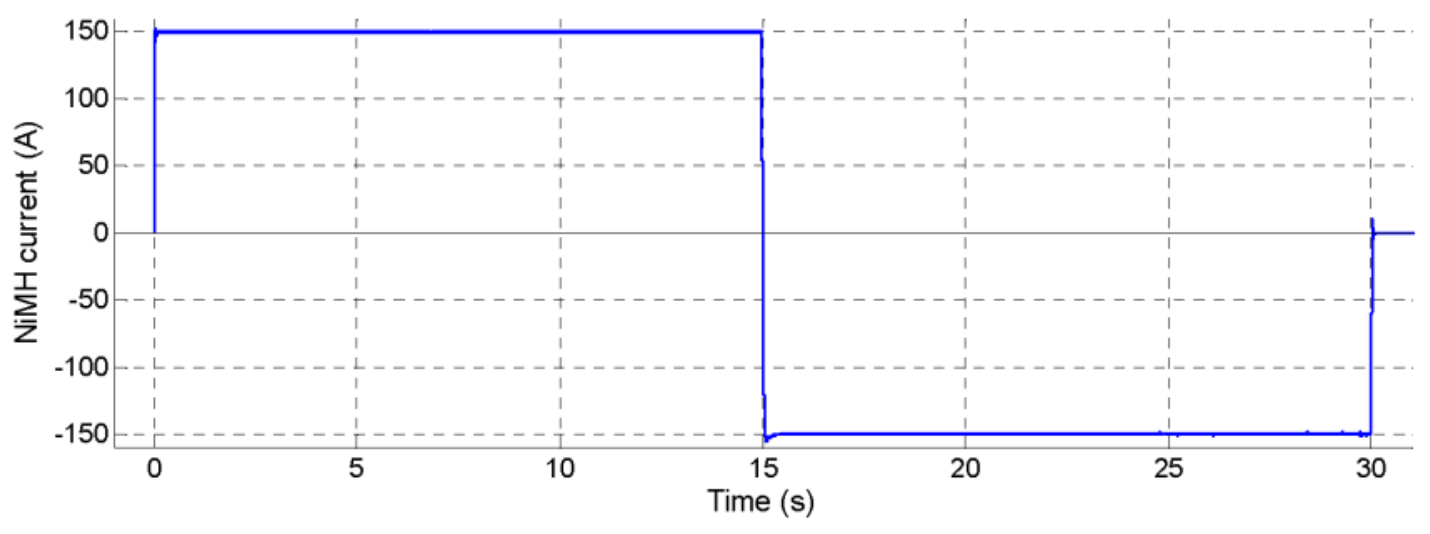

Figure 8: Performance example: 150 A discharge-charge cycle.

the rate of change, slopes up to $150 \mathrm{~A}$ in 20 milliseconds (7500 A per second) are successfully achieved. Fig. 8 shows a 150 A discharge-charge cycle with such change rate.

The system efficiency has also been assessed. There are many well-known sources of losses in the platform, the most remarkable being:

- Copper and iron losses in the transformer.

- Switching and conduction losses in both power electronics converters.

- Joule losses in all six inductances, wires, and connections.

These losses are strongly dependent on the load (ESS current), the converters switching frequency, and the DC/DC voltage conversion ratio. These dependencies are illustrated in Fig.9, in which the power system efficiency (ESS and control system power consumption not included) is depicted. This efficiency was calculated from measurements during tests with ultracapacitors. The graphic clearly shows how the efficiency drops with the ESS current for medium and high currents. It is also clear that increasing the switching frequency from $5 \mathrm{kHz}$ to $10 \mathrm{kHz}$ implies a $1-2 \%$ efficiency loss. Worsening (increasing) the $\mathrm{DC} / \mathrm{DC}$ voltage conversion ratio also causes an efficiency drop.

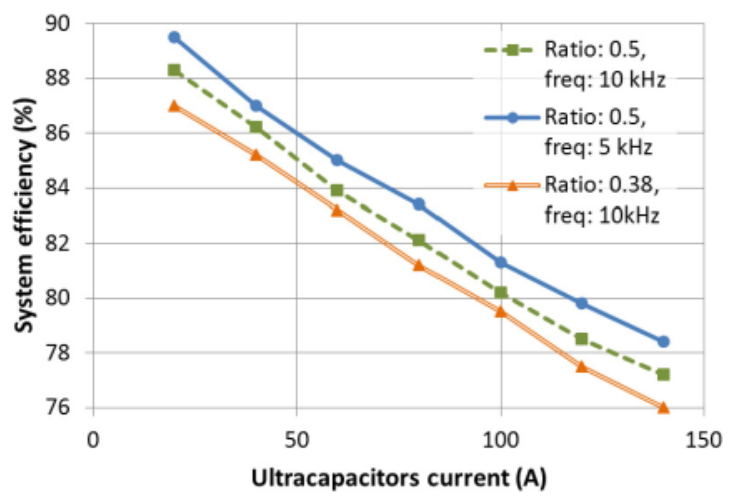

Figure 9: Power system efficiency as a function of charge/discharge current.

Regarding the cost of the whole platform, Table 1 shows the approximate price of the equipment used to assemble the system. Comparing the total cost with that of commercial solutions with the same functionality, it may be concluded that the proposed platform is clearly more economic.

Table 1: System cost.

\begin{tabular}{|c|c|c|c|}
\hline Equipment & Price $(€)$ & Quant. & Total $(€)$ \\
\hline Transformer & 1000 & 1 & 1000 \\
\hline Converters & 2250 & 2 & 4500 \\
\hline Inductances & 200 & 6 & 1200 \\
\hline $\mathrm{DSP}+\mathrm{PC}$ & 4000 & 1 & 4000 \\
\hline Sensors & 150 & 5 & 750 \\
\hline Other & - & - & 800 \\
\hline & & & 12250 \\
\hline
\end{tabular}

\section{Test example: ARTEMIS urban cycle with NiMH batteries}

As an example of the functionality of the system, test results will be presented in this section. The chosen test is not the typical constant-current or constant-power charge/discharge, but a much more 
vehicle-related test: an urban driving cycle. This results in a much more interesting test, since the EES works in exactly the same way as it would in a vehicle: aggressive and soft accelerations, regenerative braking, and so on. Although in this example the battery performance is tested during driving conditions, many other tests can be performed with this platform, avoiding the difficulties related to on-board tests.

The chosen driving cycle was the ARTEMIS urban cycle, belonging to the ARTEMIS European driving cycles [12]. These cycles were built-up to be representative of the actual conditions of vehicle usage and driving and to reproduce the diversity of the observed driving conditions. Such driving cycles present a real advantage as they are derived from a large database, using a methodology that was widely discussed and approved. They are probably the results of the most advanced works in that area, according to their author [12].

The chosen cycle, shown in Fig.10, is a 17minute urban cycle in completely flat terrain. It has an average speed of $17.5 \mathrm{~km} / \mathrm{h}$ and a running speed of $24.4 \mathrm{~km} / \mathrm{h}$. In all, 21 stops lead to a stop total duration of $28 \%$ and a rate of 4.7 stops per $\mathrm{km}$.

To perform the test, a NiMH battery pack was used. Table2 summarizes the battery technical data.

Table2: NiMH battery pack data.

\begin{tabular}{|c|c|c|c|}
\hline Voltage & $\begin{array}{c}12 \mathrm{~V} / \\
\text { module }\end{array}$ & Weight & $\begin{array}{c}18.6 \mathrm{~kg} / \\
\text { module }\end{array}$ \\
\hline Capacity & $\begin{array}{c}100 \mathrm{Ah} \\
(\mathrm{C} / 3)\end{array}$ & Config. & $\begin{array}{c}4 \text { modules } \\
\text { in series }\end{array}$ \\
\hline $\begin{array}{c}\text { Specific } \\
\text { Energy }\end{array}$ & $\begin{array}{c}66 \\
\mathrm{~W} / \mathrm{kg}\end{array}$ & $\begin{array}{c}\text { Specific } \\
\text { Power }\end{array}$ & $150 \mathrm{~W} / \mathrm{kg}$ \\
\hline
\end{tabular}

To derive the instantaneous current provided/absorbed by the batteries from the speed reference defined by the ARTEMIS cycle, a simulation was performed. A real commercial electric vehicle was modelled in SIMULINK $\mathbb{R}$, taking into account the following elements:

- The ESS (a $330 \mathrm{~V}$ NiMH battery pack).

- A DC/AC converter of enough power, including the corresponding capacitive and inductive filters.

- The electrical machine (a $35 \mathrm{~kW}$ permanent

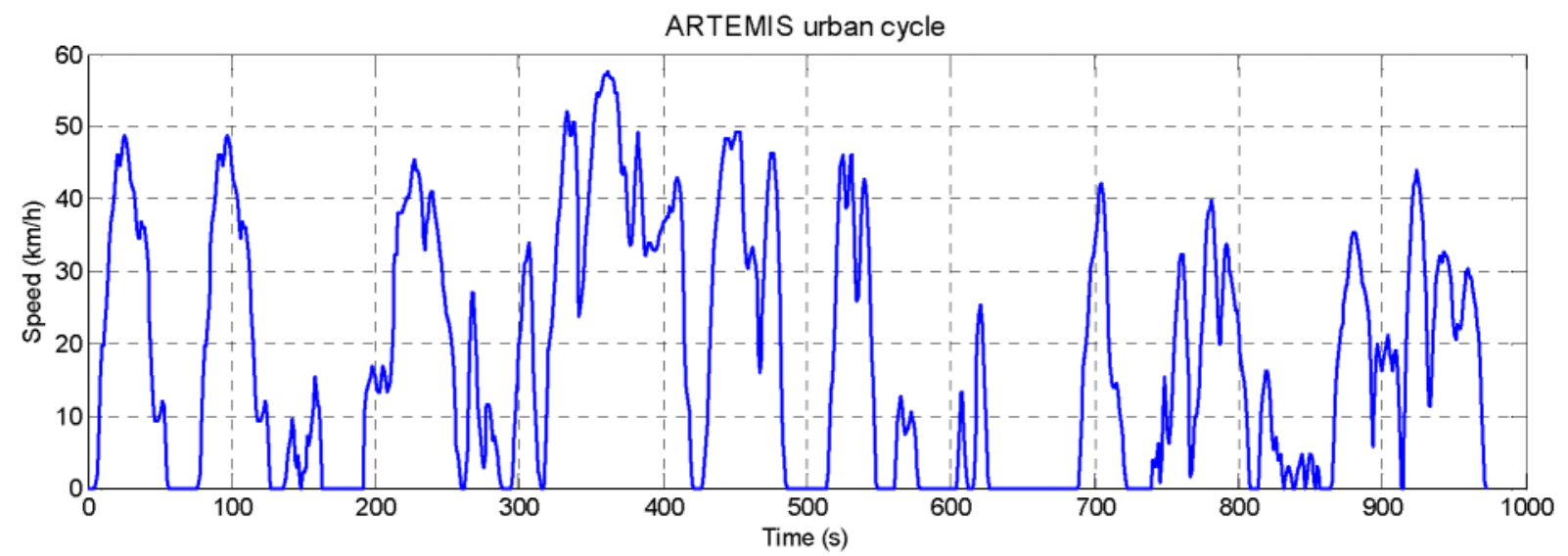

Figure 10: ARTEMIS urban cycle (speed vs. time).

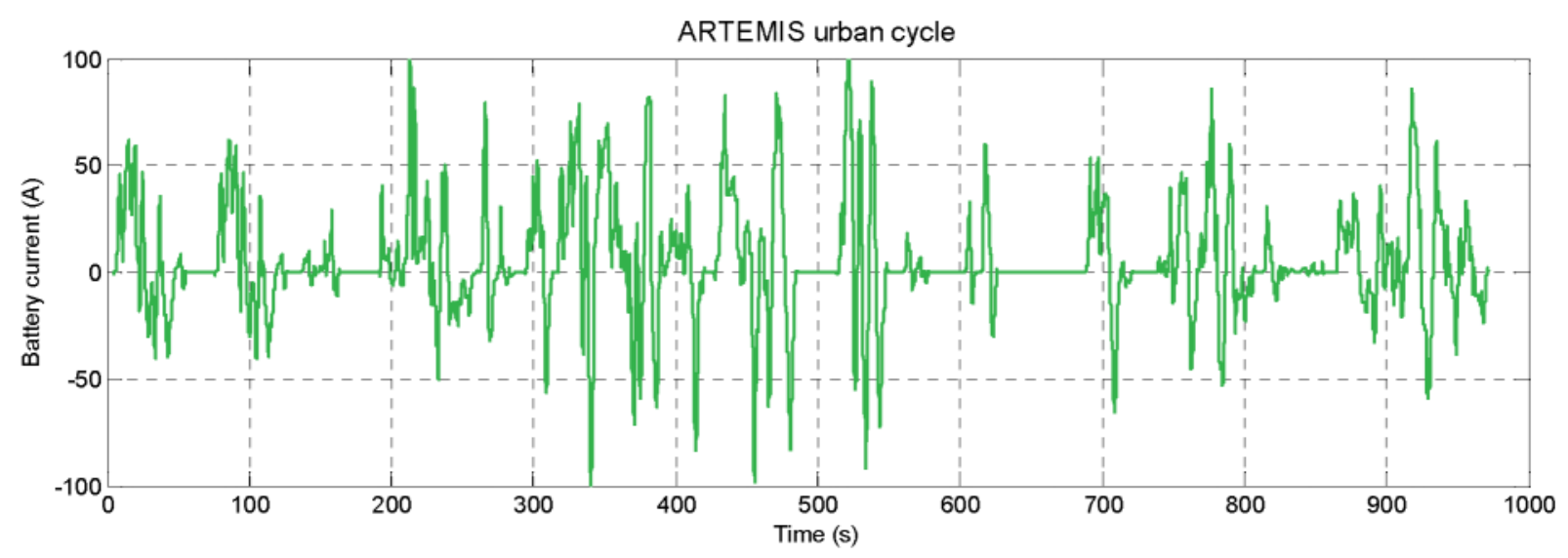

Figure 11: Battery current setpoint during the ARTEMIS urban cycle. 
magnet synchronous machine with a maximum torque of $180 \mathrm{Nm}$ ), taking saturation and copper losses into account (and neglecting iron losses).

- The powertrain transmission.

- The wheels properties.

- The total mass of the vehicle (curb mass plus one passenger).

- Motion resistances: aerodynamic drag and rolling friction (in this case gravitational resistance is not applicable, since the cycle is completely flat).

- And the urban cycle itself.

Simulations were run, so that the virtual vehicle drove a virtual ARTEMIS urban cycle. As a result, the battery current (instantaneous values) was obtained. The fundamental component of this current is depicted in Fig.11. In that graphic, strong acceleration peaks and deep regenerative braking are shown, as expected.

That current was used as a reference during the laboratory test, effectively making the $\mathrm{NiMH}$ pack work as if it was performing the urban cycle.

It is worth noting that during the tests the actual current is not exactly equal to the reference, since the power electronics switching imply certain current ripple (AC harmonics). However, some ripple is also present in the real vehicle, given that a converter is also drawing current form the battery pack. Naturally, both ripples may have little in common, but this is a limitation that the authors cannot overcome, since it is due to lack of very specific information (such as the DC filter and the switching frequency of the power electronics in the real vehicle). Nevertheless, in both cases the same DC current is flowing from the battery pack, and in both cases a power electronics converter is responsible for the current ripple, so the testing capabilities of the proposed platform are proved regardless the actual accuracy of these specific results. The goal of this particular test is not to draw conclusions regarding the NiMH batteries and the commercial vehicle, but to prove the functionality of the proposed test bench.

Fig. 12 shows part of the test results (in the range of 860-910 seconds within the ARTEMIS cycle). The whole cycle is not depicted so that some current ripple may be observed in the actual battery current (otherwise the time scale would not allow for these details to be appreciated). In this
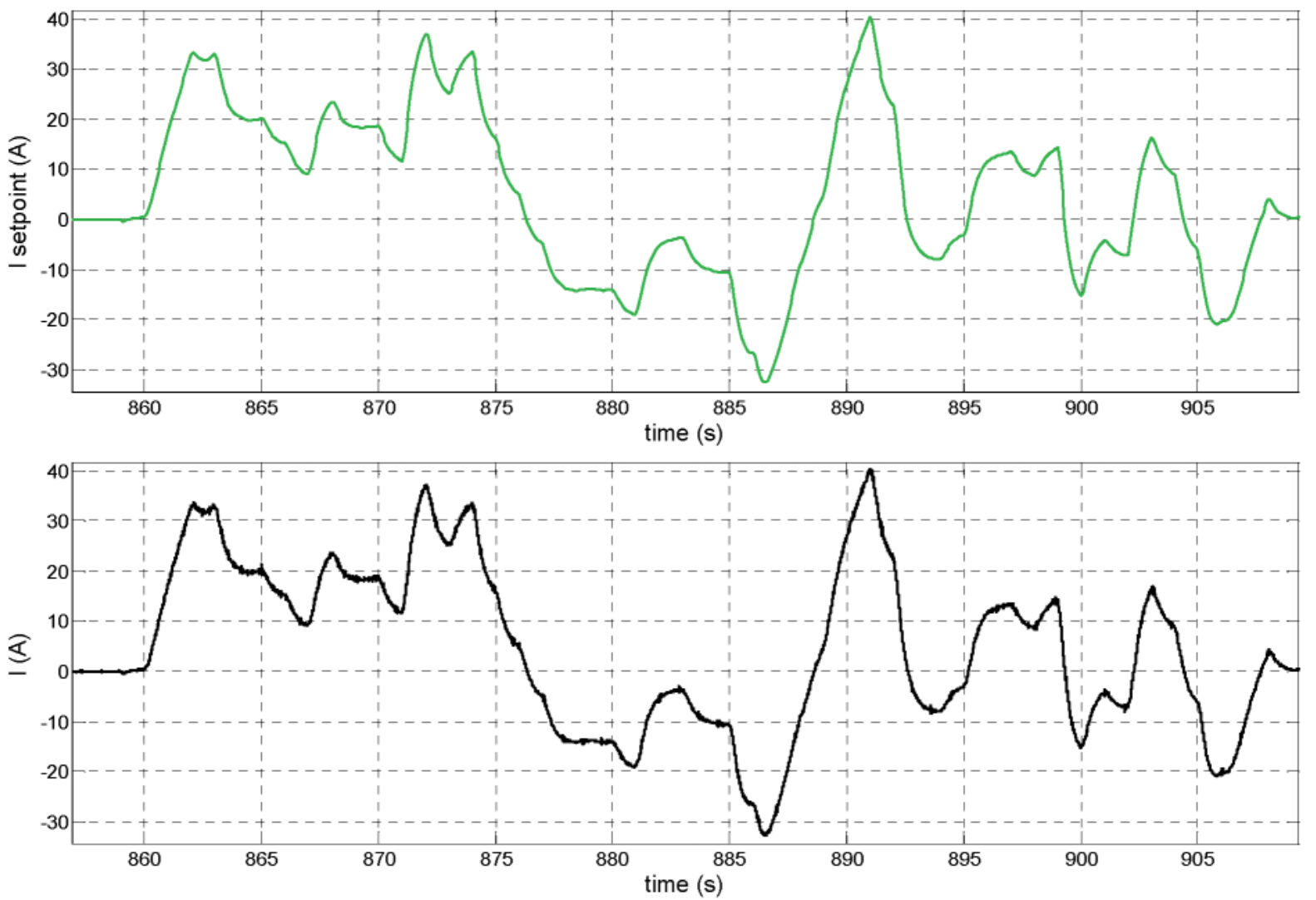

Figure12: Test results: battery current reference and actual battery current (filtered) during part of the ARTEMIS cycle. 
particular test, the system follows the reference accurately, performing 17 minutes of test during which the battery voltage dropped from $50.1 \mathrm{~V}$ to $49.7 \mathrm{~V}$.

\section{Conclusions}

This paper proposes a laboratory system specifically designed to test batteries and ultracapacitors for hybrid and electric vehicles. The advantages of the proposed platform are not its novelty or its cutting-edge technology, but its flexibility, relative simplicity, and cost.

The flexibility is a must when testing energy storage systems for vehicles, since they must satisfy very demanding working conditions that are not usual in other applications. In this sense, specific tests must be performed in order to draw accurate conclusions about their behaviour. Conventional constant-current or constant-power charge/discharge tests are not enough anymore; it is undeniably interesting to make the ESS work in the same way as it would in a driving cycle. This results in the EES operating in exactly the same way as it would in a vehicle, including aggressive accelerations and regenerative braking.

Flexibility usually comes at a high cost. There are commercial platforms capable of performing the aforementioned tests. However, they are rather expensive.

The proposed system is capable of performing such tests but with a much lower investment. It fulfils both the flexibility and cost requirements at the same time. This highly customizable system allows ESS to be tested in many and varied ways, effectively emulating the working conditions that they face in an electric vehicle.

As an example of the functionality of the platform, a test consisting of an ARTEMIS urban cycle with a NiMH battery pack has been presented. Based on simulations, a battery current profile has been derived from a speed profile. Then, this current profile has been introduced as the current reference for the battery. This way, the battery performance is tested according to specific driving conditions, although many other tests can be performed with the proposed system. The results prove the functionality of the system.

\section{Acknowledgments}

The authors gratefully acknowledge Juan Carlos Ballesteros and Pablo Fontela of ENDESA GENERACIÓN S.A. for their collaboration in this work.

This work was supported in part by the SEGVAUTO Project ("Convocatoria de ayudas para la realización de programas de actividades de $I+D$ entre grupos de investigación de la CAM en tecnologias", ORDEN 679/2009, 19 Feb. Ref: S2009/DPI-1509).

\section{References}

[1] D. U. Sauer, The battery - Bottleneck for the E-mobility?, Workshop of The Dutch Royal Institute of Engineers, 2010.

[2] J. Christensen et al., A Critical Review of Li/Air Batteries, Journal of the Electrochemical Society, Vol. 159, issue 2, R1-R30, 2012.

[3] S. Hu, R. Rajamani, X. Yu; Flexible solidstate paper based carbon nanotube supercapacitor, Applied Physics Letters, Vol. 100, 104103-104103-4, 2012.

[4] R. Clague, I. Siera, M. Lamperth; Supercapacitor Enhanced Battery Traction Systems - Concept Evaluation, EVS23 and World Electric Vehicle Journal Vol. 2, 2008.

[5] R. Clague, I. Siera, M. Lamperth; A Novel Hybrid Control Strategy for Maximising Regenerative Braking Capability In a Battery-Supercapacitor Energy Storage System, EVS25 and World Electric Vehicle Journal Vol. 4, 2010.

[6] M. André, The ARTEMIS European driving cycles for measuring car pollutant emissions, Science of The Total Environment, Vol. 334335, pages 73-84, 2004.

[7] M. Huang, Y. Chang, P. Yeh, C. Lu; Comprehensive Design of an Isolated $A C-D C$ Converter to Emulate On-road Current of Electrical Scooter for Testing Lithium Battery, IEEE Energy Conversion Congress and Exposition (ECCE), 2012.

[8] H. H. Eroglu, A. M. Hava; Design and Implementation of an Ultracapacitor Test System, IEEE International Symposium on Industrial Electronics (ISIE), 2011.

[9] T. Blank et al., Design and construction of a test bench to characterize efficiency and reliability of high voltage battery energy storage systems, $32^{\text {nd }}$ International Telecommunications Energy Conference (INTELEC), 2010. 
[10] I. Trintis et al., Bidirectional Converter Interface for a Battery Energy Storage Test Bench, $14^{\text {th }}$ European Conference on Power Electronics and Applications (EPE), 2011.

[11] S. Zhang, X. Yu; A Unified Analytical Modeling of the Interleaved Pulse Width Modulation (PWM) DC-DC Converter and Its Applications, IEEE Transactions on Power Electronics, Vol. 28, issue 11, 2013.

[12] Michel ANDRÉ, Real-world driving cycles for measuring cars pollutant emissions Part A: The ARTEMIS European driving cycles, Report INRETS-LTE 0411, June 2004.

\section{Authors}

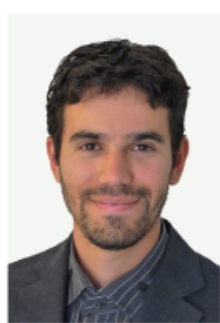

Pablo Concha received the M.Sc. degree in Electrical Engineering from the Universidad Politécnica de Madrid, SPAIN, in 2010. He is currently working in the Research Centre on Energy, Environment and Technology (CIEMAT, SPAIN). He is also coursing the Ph.D. in Electrical Engineering in the mentioned university.

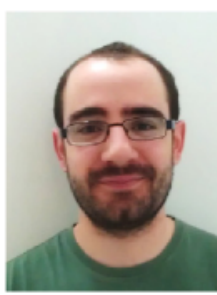

Pablo Vélez is currently coursing the M.Sc. degree in Electrical Engineering in the Universidad Politécnica de Madrid, SPAIN. This work is part of his Master Thesis.

Marcos Lafoz Pastor received the Ph.D. degree in Electrical Engineering in 2005 from the Universidad

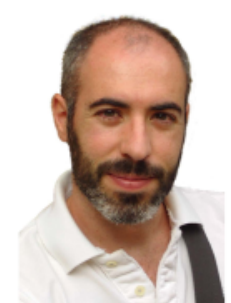
Politécnica de Madrid. He is currently working in the Research Centre on Energy, Environment and Technology (CIEMAT, SPAIN). Since 2000 he participates as Assistant Lecturer in the Universidad Politécnica de Madrid, teaching Electric Motor Drives.

Jaime R. Arribas received the Ph.D. degree in Electrical Engineering from the Universidad Politécnica de Madrid in 2000. Since 1992 he has worked in the Electrical Engineering Department at the Faculty of Industrial Engineers of the Universidad Politécnica de Madrid, teaching graduate and postgraduate courses in Electrical Machines and their control. 